\title{
Challenges in Pandemic Disaster Preparedness: Experience of a Saudi Academic Medical Center
}

\author{
Wajdan AlAssaf, MD
}

\section{ABSTRACT}

In December 2019, a pneumonia of unknown etiology was detected in Wuhan, China. This outbreak was then declared an international public emergency in January 2020 by the World Health Organization (WHO), and the announcement activated disaster management plans worldwide. This global crisis created several challenges for the health-care sector. This study reviews the challenges faced by a middle-sized urban academic hospital that are likely present to some extent in all health-care sectors, regardless of their existing disaster plans and policies. While preparing this Saudi academic hospital with a capacity of 192 beds for the emerging pandemic, obstacles arose despite its extensive prior disaster planning and training. Specifically, these challenges were related to health-care workers, supplies, and patient care. We review the actions taken to overcome and resolve these difficulties and provide future planning suggestions for each area to potentially assist other hospitals in their disaster planning and preparedness. Key Words: mass gathering medicine, communicable diseases, organizational decision-making, disaster planning, disaster medicine

A lthough disaster preparedness is an integral part of hospital policies and procedures, ${ }^{1}$ hospital preparedness before the coronavirus disease 2019 (COVID-19) pandemic focused in improving surge capacity, or the "health-care system's ability to manage a sudden or rapidly progressive influx of patients within the currently available resources at a given point in time." ${ }^{2}$

Pandemic disaster preparation poses many challenges, basically in ensuring that strategic, tactile, and operational plans are comprehensive in addressing community and health-care needs. ${ }^{3}$ Hospital teams in rural hospitals perceived that improving the treatment and management processes for patients with infectious diseases was highly important, yet training the teams assigned to patient isolation was at the bottom of the list of those priorities, Building staff capability and capacity is a major component of hospital surge planning that involves personnel, supplies, equipment, and structure. ${ }^{4,5}$

During the COVID-19 pandemic, the nature of the disease and associated uncertainties imposed increased risk and pressure on numerous hospitals areas, for example, intensive care units (ICUs) use, patient care in the emergency department (ED), and special precautions implementations in operating rooms. ${ }^{6-8}$

As few papers review this specific topic, we aim to briefly discuss the primary challenges that were encountered and how we dealt with each one of them, as well as how we intend to prevent and manage them in the future (Table 1).

\section{METHODS}

In this concept paper, the experience of our academic hospital with a current capacity of 192 beds, including $23 \mathrm{ED}$ beds (7 isolation beds), 31 adult critical care, 17 neonatal ICU (NICU), and 11 pediatric ICU (PICU) beds, with current overall medical staff of 607 individuals, and a nursing staff of 557, will be shared.

When the World health Organization (WHO) announced that the spreading pneumonia (later called COVID-19) was a public health emergency of international concern, a COVID-19 Task Force team was created on February 4, 2020 (started with weekly meetings, then daily meetings 3 wk later). A daily census of cases, admissions, supplies, equipment, bed status, and available personnel was tallied, including all challenges faced in the previous day, and discussed in those daily meetings. Additionally, all suggestions and input from hospital members were discussed for the feasibility of implementation; conclusions and resolutions were implemented immediately by contacting chairmen and managers of concerned departments.

In the following sections, we will describe the process of dealing with the challenges (related to health-care workers, supplies, and patient care), how we overcame 


\section{TABLE 1}

\section{Challenges Faced in Pandemic Hospital Disaster}

Preparedness

Patient care:

- Screening and isolation

- Receiving and discharging patients

- Cardiac arrest codes

- Continuity of patient care

Health-care workers:

- Communication

- Curfew

- Risk of infection

Supplies:

- PPE

these challenges, what worked for us as a final solution, and how can we can prevent them in the future.

\section{PATIENT CARE-RELATED CHALLENGES Screening and Isolation}

Uncertainty was the norm during the initial phase. Screening checklists were distributed to all health-care facilities by the Saudi CDC detailing the cardinal symptoms and criteria that mandated swabbing, with frequent updates on the regions of high concern that were considered as initial outbreak areas.

Although guidelines were distributed, the teams were unable to readily apply them in many cases, and the list underwent frequent changes, which made things worse.

\section{Solution}

To ease the stress and help guide our team we did the following: (1) We provided a 24/7 on-call representative of our infection control (IC) department, available to answer all calls and help in decision-making. (2) We created and distributed algorithmic pathways through emails, social communication applications (WhatsApp), and printed them on laminated A3 papers and posted them in the frontline locations.

\section{Suggested Future Solutions}

The use of phone and computer applications to help guide the team in decision-making in such a situation will decrease the risk of poor judgment and lessen confusion.

\section{Receiving and Discharging Patients}

During mass causality incidents, patient throughput in the ED is based on categorization by triage, with no need to focus on isolating these patients from other patients (with the exception of certain types of disasters as chemical, biological, radiological, and nuclear incidents). With COVID-19, it was imperative that suspected COVID-19 patients did not come in contact with other ED patients as an IC measure.
Due to the previous Middle East respiratory syndrome coronavirus (MERS-CoV) outbreak that started in 2012, Saudi hospitals had been mandated by the Ministry of Health to have separate respiratory zones. The challenge that arose with COVID-19 was the high influx of worried patients and those with nonspecific symptoms, which added extra pressure on our limited respiratory zone ( 7 beds). In addition, each case was unique, and no specific decision could be applied to all: while you may swab patient $A$ and send him/her for home isolation, you may have to admit patient $B$, who came with the exact same complaints but with different social conditions.

Patients flow had to be strictly controlled to prevent mixing infected patients with other ED patients, including a separate admission route to minimize in-hospital movement. Previous bed occupancy rate in the medical ward was less than $70 \%$ of the initial 26 medical beds, and adult ICU was less than $40 \%$ of the 14 beds; during the pandemic, a floor was assigned to cohort patients (including critical care cases) with 72 regular beds and 22 ICU beds. At 1 stage, we reached 100\% occupancy rate in the medical beds.

\section{Solutions}

(1)We simulated and tested the entire process starting from patient arrival and ending with either admission or discharge. (2) We expanded the respiratory zone, and added extra boarding rooms in the ED with a separate passage for patients' movement. (3) We assigned 2 elevators for moving admitted COVID-19 patients to their floors, not to be used by staff, or other patients under any circumstances. (4) We assigned a quarantine building for positive asymptomatic patients, where they were accommodated in single rooms, with an onsite medical team to decrease the pressure on hospital beds.

\section{Suggested Future Solutions}

The structures for screening and isolation solutions can be applied here. Online guides can be provided by applications that are based on answering specific questions to provide the optimal disposition of each case.

\section{Cardiac Arrest Codes}

Responding to the cardiac arrest code had always been a straightforward practice, yet COVID-19 added extra challenges, including limiting the number of personnel, assessing the appropriateness of resuscitation, and maintaining team protection, ${ }^{9}$ as well as shifting from an autopilot mentality to full situational awareness during codes.

\section{Solutions}

(1) We implemented a simulation-based training based on the available resuscitation recommendations. Multiple deficiencies and drawbacks were experienced regardless of the department (ED, ICU, respiratory therapy, nursing, and ward physicians). These issues necessitated the implementation of 
daily mock codes with prolonged multidisciplinary debriefings. (2) We assigned senior trainers to continue the educational and training process after training the entire team. (3) We created simplified response algorithms by a panel of experts and laminated them and placed them on all crash carts to be easily observed and reviewed by response teams on their way to any code call.

\section{Suggested Future Solutions}

Hospital disaster preparedness should involve all aspects of patient care. Having disaster teams that include representatives from all hospital areas is of paramount importance in avoiding fragmentation.

\section{Continuity of Patient Care}

Continuity of care was affected by many factors; Fear of visiting the hospital prevented some patients with chronic illnesses from showing up to their follow-up appointments. Additionally, clinics were shut down later because of city wide curfew, we kept 4 functional clinics: family/employee, flu clinic, pediatric walk-in, and OB/GYN. The number of patients permitted at any 1 time was also decreased.

\section{Solutions}

(1) We initiated tele-medicine clinics to follow up on patients with chronic illnesses. (2) We created a phone-based medication refill clinic to prevent patients from running out of prescriptions. (3) We signed a contract with local postal carriers to deliver medications to patient's homes.

\section{Suggested Future Solutions}

Activation of telemedicine and virtual clinics will be an excellent mitigation aid and would be helpful even under normal circumstances to decrease hospital visits for those presenting for medication refills or regular follow-ups.

\section{HEALTH-CARE WORKER-RELATED CHALLENGES Communication}

The ED had to be divided into 2 sections: respiratory and regular (clean) zones. Those in the respiratory zone were not permitted to leave their area, to prevent the spread of infection and to preserve personal protective pquipment (PPE) resources by decreasing frequent donning and doffing. In addition, the triage and eyeball areas (initial visual screening area of ED patients) of the respiratory and clean zones were in different locations. Upon arrival, patients were greeted by the eyeball (initial screening) nurses, who checked their temperature, provided them with alcohol gel for hand hygiene, and offered them a face mask. The patients will be asked about any respiratory symptoms and risk factors for COVID-19 infection.

Using landlines and cell phones was useful for relaying interpersonal messages between 2 individuals, but not for group communication (eg, the patient is in respiratory zone receiving area, this patient will need to be shifted to a boarding area, and a patient is expected to come for swabbing). Communication within the ED had always been an issue; COVID-19 presented numerous additional challenges, all of which required swift procedural changes.

\section{Solutions}

(1) We used a hands-free, push-to-talk, free phone application (Zello Walkie Talkie), to create a channel for our ED team (nurses, physicians, and administrative workers). Those on duty turned on this application and were able to remain aware of situations throughout the entire ED. The team used their personal cell phones, which were sealed by double plastic covers that were cleaned by alcohol after each use and disposed of at the end of the shift.

(2) We created a WhatsApp group to keep track of patients who were swabbed either in the ED or flu clinic, being sent to ED for direct COVID-19-related admission, or being sent back to the hospital for re-swabbing (this process is between IC department, nurses and physicians). The group included IC and nursing team leaders, where the patient file number with the requested/completed procedure (swab, admission, or re-swab) was posted immediately.

\section{Suggested Future Solutions}

With the advances of technology, communication thorough secure cell phone channels that include all team members working in the same area is especially easy. Hospital information technology departments can begin creating, encrypting, and using such modalities to make them ID-based accessible to maintain the security of sensitive clinical information.

\section{Curfew}

After curfew was announced by the government (March 22), movement was limited to those with active valid permits. The process of issuing permits took some time, because they required signatures and validation by multiple governmental sectors. Hence, numerous $\mathrm{HCW}$ s were unable to come to work until their permits were finalized, while others were issued fines because of a lack of a permit. Commonly used paid transportation services were put on pause. Additionally, some female employees did not know how to drive and were dependent on drivers to commute, who also faced challenges in obtaining permits.

\section{Solutions}

(1) We modified the on call/shift schedules to synchronize work schedules with university campus housing schedules each week. (2) We used the university dorms/housing to accommodate staff who worked in critical care/ED. 
FIGURE

A sample of the printed educational materials posted.

\begin{tabular}{|c|c|c|c|c|c|c|c|c|c|}
\hline \multirow[t]{2}{*}{$\begin{array}{c}\text { Hospital } \\
\text { Area }\end{array}$} & \multirow[t]{2}{*}{$\begin{array}{l}\text { Targeted } \\
\text { Personnel }\end{array}$} & \multirow[t]{2}{*}{ Activity } & \multicolumn{7}{|c|}{ Type of PPE } \\
\hline & & & $\begin{array}{l}\text { Surgical } \\
\text { Mosk }\end{array}$ & N95 Mask & $\begin{array}{l}\text { Eye } \\
\text { Protection } \\
\text { (goggle or }\end{array}$ & $\begin{array}{l}\text { Yellow } \\
\text { Gown }\end{array}$ & $\begin{array}{l}\text { Water- } \\
\text { repellent } \\
\text { Gown }\end{array}$ & $\begin{array}{l}\text { Non- } \\
\text { Sterile } \\
\text { Gloves }\end{array}$ & $\begin{array}{l}\text { Head } \\
\text { Cover }\end{array}$ \\
\hline \multicolumn{10}{|c|}{ EMERGENCY DEPARTMENT } \\
\hline $\begin{array}{l}\text { Respiratory } \\
\text { Triage }\end{array}$ & $\mathrm{HCW}$ & $\begin{array}{l}\text { Preliminary screening with no direct patient contact } \\
\text { - Maintain } 1.5 \text { meter spatial distance at all time }\end{array}$ & & & & & & & \\
\hline $\begin{array}{l}\text { Patient } \\
\text { Waiting Area }\end{array}$ & Patients & $\begin{array}{l}\text { Patient with respiratory symptoms } \\
\text { - Patient should be seated at a designated area and to sit at } \\
\text { least } 1.5 \text { meter }\end{array}$ & & & & & & & \\
\hline \multirow[t]{2}{*}{$\begin{array}{l}\text { Examination } \\
\text { Room / } \\
\text { Consultation } \\
\text { Room } \\
\end{array}$} & $\mathrm{HCW}$ & $\begin{array}{l}\text { History taking \& Physical Examination } \\
\text { - Patient should be reminded to wear a surgical mask when } \\
\text { the HCW enters the room }\end{array}$ & & & & & & & \\
\hline & Housekeeping & $\begin{array}{l}\text { Cleaning in the outpatient consultation rooms } \\
\text { - Increase frequency of cleaning at areas with higher } \\
\text { environmental contamination rates }\end{array}$ & & & & & & & \\
\hline
\end{tabular}

\section{Suggested Future Solutions}

(1) Improving a national database for HCWs, especially those working in critical care areas and front liners, to exclude them from any curfew legislation. (2) Implementing technology-based staff registration and filing this database with governmental agencies would have a tremendous effect in preventing such issues.

\section{Risk of Infection}

Before the pandemic, the practice of in-hospital clothes changing was not implemented. When positive cases began to appear in the region, the teams were instructed to practice a strict clothes changing policy to decrease the risk of transmitting infection outside the institution, this policy added an extra burden to our already thinly stretched laundry services.

In addition, while our attention was focused on HCWs, we discovered that ancillary staff had not been taken into consideration as they should have been, although they are also at tremendous risk (a common observation on pandemic/epidemics), ${ }^{10}$ and the hospital functionality depends upon them. Without proper training and education for this workers group, there is a risk of the spread of infection as well as delay in rooms turnover. ${ }^{11}$

Number and duration of duties continued the same for $\mathrm{HCW}$, but those who were not on call or covering the services were advised to refrain from coming to the hospital.

\section{Solutions}

(1) We implemented a hospital-wide policy clearly mandating that the staff are required to adhere to clothes changing rules when entering and leaving the hospital. (2) We prepared clothes-changing areas. (3) We established a scrubs/lab coats storage area inside the ED, ICU, and PICU for staff convenience. (4) We provided an intense hands-on training of proper PPEs use and cleaning protocols for ancillary services personnel. (5) We postponed in-hospital rotation of ancillary services personal and the younger, healthy service personnel were assigned to critical and COVID-19 areas. (6) We provided on-campus housing for such personnel.

\section{Suggested Future Solutions}

Annual training in IC measures of both HCWs as well as ancillary service workers and requiring this as part of re-contracting competencies.

\section{SUPPLIES-RELATED CHALLENGES \\ PPE}

PPE is of paramount importance in protecting HCWs and decreasing the risk of infection. The nature of the COVID19 pandemic created a global demand for PPE, owing to the high consumption.

Uncertainty surrounded the mode of transmission of COVID-19 virus during the initial phase. Initially, it was approached as droplet generated, then rumors emerged regarding the possibility of airborne spread. As a result, HCWs were confused about what type of PPE should be used and when, loss of trust in institutional IC recommendations was an additional challenge. 
Unsurprisingly, PPE consumption skyrocketed due to extra precaution measures.

\section{Solutions}

(1) We conducted mass education for HCWs and supporting services regarding the proper use of PPE. (2) We assigned auditing teams, provided with intense education by the IC team, who rotated throughout the hospital to monitor donning, doffing, and the appropriateness of PPE use. Critical areas, such as the ED, ICUs, and COVID-19 admission ward were monitored $24 / 7$, any breach or misconduct was approached immediately and resolved. (3) We distributed educational material by posting visual aids on the hospital intranet and distributing them through email; the easiest aid was a printed schedule with all PPEs in columns, and the scenarios in rows, and checkmarks were added (a sample is presented in Figure 1).

\section{Suggested Future Solutions}

The use of visual aids showed great effect on delivering the messages simply (based on internal staff feedback). Written recommendations may be difficult to memorized or even comprehended during stressful situations; hence, a simple visual aid is the easiest go-to reference.

\section{CONCLUSIONS}

Pandemics are less common than mass causality incidents. Additionally, their score is lower in hazard vulnerability analysis. Our experience was an eye-opening one regarding the necessity of multidisciplinary planning and thorough hospital disaster preparedness in consideration of the specific nature of pandemics (eg, change in daily practice, worldwide demand on the same supplies, and confusion and cognitive overload), and the necessity of building integrated strategic, tactile, and operational plans for pandemic preparedness. ${ }^{3}$

\section{About the Author}

College of Medicine, Princess Nourah Bint Abdulrahman University, Riyadh, Kingdom of Saudi Arabia.
Correspondence and reprint requests to Wajdan AlAssaf, College of Medicine, Princess Nourah Bint Abdulrahman University, 3209 jabal aseeb street, unit 1, Riyadh, Kingdom of Saudi Arabia (e-mail: wajdan.alassaf@gmail.com).

\section{REFERENCES}

1. Kaji AH, Koenig KL, Lewis RJ. Current hospital disaster preparedness. JAMA. 2007;298(18):2188-2190. doi: 10.1001/jama.298.18. 2188

2. American College of Emergency Physicians (ACEP). Health care system surge capacity recognition, preparedness, and response. Policy statement. Ann Emerg Med. 2012;59(3):240-241. doi: 10.1016/j.annemergmed.2011. 11.030

3. Burkle FM Jr. Do pandemic preparedness planning systems ignore critical community- and local-level operational challenges?. Disaster Med Public Health Prep. 2010;4(1):24-29. doi: 10.1097/dmp. Ob013e3181cb4193

4. Manley WG, Furbee PM, Coben JH, et al. Realities of disaster preparedness in rural hospitals. Disaster Manag Response. 2006;4(3):80-87. doi: 10. 1016/j.dmr.2006.05.001

5. Koenig K, Schultz C. eds. Koenig and Schultz's Disaster Medicine: Comprehensive Principles and Practices. Cambridge: Cambridge University Press; 2016. doi: 10.1017/CBO9781139629317

6. Grasselli G, Pesenti A, Cecconi M. Critical care utilization for the COVID-19 outbreak in Lombardy, Italy: early experience and forecast during an emergency response [published online ahead of print, $2020 \mathrm{Mar} 13$ ]. JAMA. 2020. doi: 10.1001/jama.2020.4031

7. Cao Y, Li Q, Chen J, et al. Hospital emergency management plan during the COVID-19 epidemic. Acad Emerg Med. 2020;27(4):309-311. doi: 10. 1111/acem.13951

8. Wong J, Goh QY, Tan Z, et al. Preparing for a COVID-19 pandemic: a review of operating room outbreak response measures in a large tertiary hospital in Singapore. Can J Anaesth. 2020;67(6):732-745. doi: 10. 1007/s12630-020-01620-9

9. Edelson DP, Sasson C, Chan PS, et al. Interim guidance for basic and advanced life support in adults, children, and neonates with suspected or confirmed COVID-19: from the Emergency Cardiovascular Care Committee and Get With The Guidelines-Resuscitation Adult and Pediatric Task Forces of the American Heart Association. Circulation. 2020;141(25):e933-e943. doi: 10.1161/CIRCULATIONAHA.120. 047463

10. Nagle LM, Vincent L. A SARS postcard-reflections of two healthcare leaders. Nurs Leadersh (Tor Ont). 2003;16(2):24-26. doi: 10.12927/cjnl. 2003.16275

11. Krajewski MJ, Sztajnkrycer M, Baez AA. Hospital disaster preparedness in the United States: new issues, new challenges. Int J Rescue Disaster Med. 2005;4(2):22-25. http://ispub.com/IJRDM/4/2/4644 